\title{
Análise do perfil sociodemográfico e do processo de trabalho do cirurgião-dentista inserido no Programa de Saúde da Família em três municípios da região serrana do Estado do Rio de Janeiro
}

\section{I ${ }^{1}$ Liliane Barbosa de Moraes, ${ }^{2}$ Débora Cynamon Kligerman, ${ }^{3}$ Simone Cynamon Cohen I}

Resumo: A inserção da odontologia no Programa de Saúde da Família teve como principal objetivo a reorganização do modelo de atenção, ampliando o acesso da população aos serviços de saúde bucal, garantindo atenção integral, mediante o estabelecimento de vínculo territorial. Nesse contexto, o estudo teve como objetivo avaliar o perfil do cirurgião-dentista inserido no Programa e analisar o processo de trabalho da equipe de saúde bucal em três municípios da região serrana do Estado do Rio de Janeiro, verificando se houve substituição do modelo tradicional de atendimento, por aquele centrado nos princípios do SUS. Realizou-se estudo exploratório baseado em entrevista. $\mathrm{O}$ perfil do cirurgião-dentista encontrado nesses municípios revelou potencialidades para a transformação das práticas em saúde bucal, mas a análise do processo de trabalho identificou pouco envolvimento desses profissionais com as condiçôes de vida da comunidade e dificuldade para trabalhar em equipes multiprofissionais. Aponta-se a necessidade de políticas públicas que incorporem programas de capacitação para que o cirurgião-dentista atue em consonância com as diretrizes do Programa de Saúde da Família.

> Palavras-chave: Odontologia em saúde pública; Programa de Saúde da Família; saúde bucal; Atenção Primária à Saúde.

\author{
1 Programa de Pós-Graduação \\ em Saúde Pública, Escola \\ Nacional de Saúde Pública, \\ Fundação Oswaldo Cruz. Rio \\ de Janeiro-RJ, Brasil. Endereço \\ eletrônico: lilianemoraes@ \\ globomail.com \\ ${ }^{2}$ Departamento de Saneamento \\ e Saúde Ambiental, Escola \\ Nacional de Saúde Pública, \\ Fundação Oswaldo Cruz. Rio \\ de Janeiro-RJ, Brasil. Endereço \\ eletrônico: kliger@ensp. \\ fiocruz.br \\ ${ }^{3}$ Departamento de Saneamento \\ e Saúde Ambiental, Escola \\ Nacional de Saúde Pública, \\ Fundação Oswaldo Cruz. Rio \\ de Janeiro-RJ, Brasil. Endereço \\ eletrônico: simoneccohen@ \\ gmail.com
}

Recebido em: 25/02/2014 Aprovado em: 02/12/2014 


\section{Introdução}

A Constituição Federal de 1988 trouxe como conquista a saúde como direito de todos e a consolidação do Sistema Único de Saúde (SUS). Representou um grande avanço, pois o modelo assistencial vigente no país até aquele momento era caracterizado "pela prática hospital-dependente, pelo individualismo, pela utilização irracional dos recursos tecnológicos disponíveis e, acima de tudo, pela baixa resolubilidade, modelo esse gerador de insatisfação da população" (OLIVEIRA; SALIBA, 2005). Com a consolidação do SUS, a saúde passou a ser considerada sob uma nova ótica. O conceito ampliado de saúde, definido no artigo 196 da Constituição da República, orienta a passagem de um modelo de atenção à saúde centrado na doença, baseado na hegemonia médica e hospitalocêntrica, para um modelo que incorpora ações de promoção, proteção e recuperação da saúde (BRASIL, 2004).

O SUS é definido pela Lei no 8.080 , de 19 de setembro de 1990, como um sistema de caráter público, formado por uma rede de serviços regionalizada, hierarquizada, com direção única em cada esfera de governo, cujos princípios básicos são: universalização, descentralização, integralidade e participação da comunidade (BRASIL, 1990).

Com o objetivo de fortalecer o SUS, em 1994, o Ministério da Saúde lançou o Programa de Saúde da Família (PSF) que prioriza ações de prevenção, promoção e recuperação da saúde da população, em substituição ao modelo tradicional de assistência primária baseado em profissionais especialistas (BRASIL, 2001A). Em 2006, o PSF se consolidou como Estratégia de Saúde da Família, por não se tratar apenas de um programa, com duração definida, e sim uma estratégia para a reorganização da atenção básica no Brasil (BRASIL, 2006). A organização do SUS a partir do PSF trouxe como vantagens: possibilidade de as famílias receberem orientaçôes periódicas a partir de sua realidade; diagnóstico precoce com maior possibilidade de cura; identificação de situações de risco; ampliação do acesso aos serviços de saúde e valorização do profissional de saúde (RODRIGUES; BONFIM, 2010).

Embora o PSF tenha sido criado em 1994, a inserção oficial da odontologia no programa só ocorreu no ano 2000, através da Portaria Ministerial $\mathrm{n}^{\circ}$ 1.444 , de 28 de dezembro de 2000. Essa inserção teve como principal objetivo a reorganização do modelo de atenção, ampliando o acesso da população aos 
serviços de saúde bucal, garantindo atenção integral, mediante o estabelecimento de vínculo territorial (BRASIL, 2000).

Até a década de 1950, a assistência odontológica era caracterizada pela falta de planejamento e avaliação e reproduzia a lógica da assistência realizada em consultórios particulares (OLIVEIRA; SALIBA, 2005). Nas décadas seguintes, caracterizou-se como um modelo de assistência odontológica predominantemente a escolares (PINTO, 2000). Durante anos, a política de saúde bucal no Brasil esteve centrada em procedimentos curativos. Só a partir do desenvolvimento da cariologia e sua incorporação em países como Estados Unidos, Inglaterra, Japão e Suécia, passou-se a entender a cárie como doença infecciosa e preconizar seu tratamento e prevenção o mais precocemente possível (WALTER, 1996). A partir de 1990, com a implantação do SUS, surgiram novos modelos assistenciais, dentre eles os vinculados ao núcleo familiar, como a Saúde da Família (RONCALLI, 2000). Dessa forma, a odontologia ampliou seu caráter preventivo.

No entanto, o desafio permanece: garantir à população brasileira um atendimento odontológico preventivo. A existência de grande demanda reprimida, as necessidades acumuladas, entre outros motivos, impedem que o modelo tradicional de atendimento seja substituído totalmente por aquele centrado nos princípios do SUS. E os procedimentos curativos continuam sendo predominantes (VILLARINHO et al., 2007).

A partir da inserção da odontologia no PSF, novas atribuições foram incorporadas ao processo de trabalho do odontólogo, priorizando a promoção à saúde dos indivíduos e da família, de forma integral. A prestação de cuidados odontológicos deixou de ser realizada apenas nas unidades de saúde e passou a incluir ações em domicílios e espaços comunitários.

Assim sendo, este estudo tem como objetivo analisar o perfil sociodemográfico e o processo de trabalho cirurgião-dentista inserido no PSF, em três municípios da região serrana do Estado do Rio de Janeiro. Considerando que o relatório mundial de saúde de 2006, denominado "Trabalhando Juntos pela Saúde", destacou a importância de se conhecer o perfil dos profissionais de saúde para a elaboração de políticas públicas e acrescentou que essas informações geralmente estão incompletas (MORITA et al., 2010), espera-se que os resultados deste estudo contribuam para o planejamento e implementação de políticas de formação e inserção do odontólogo nas equipes de Saúde da Família. 


\section{Material e método}

Trata-se de estudo de caráter exploratório e descritivo. Exploratório, porque a assistência odontológica dentro do PSF necessita ser mais bem estudada, por representar um novo modelo. E descritivo, pois serão detalhadas as atividades da equipe de saúde bucal dentro do PSF. O delineamento definido para a pesquisa foi o estudo de campo. Foi realizado nas Unidades de Saúde da Família que possuem Equipe de Saúde Bucal nos municípios de Teresópolis, Sumidouro e São José do Vale do Rio Preto, nos meses de março a maio de 2013, utilizando metodologia qualitativa.

O município de Teresópolis, situado na região serrana do Estado do Rio de Janeiro, possui 777,14 Km de área, uma população (segundo o Censo 2010) de 163.746 habitantes, densidade demográfica de 210,78 hab $/ \mathrm{km}$. O valor do Índice de Desenvolvimento Humano Municipal (IDHM) 2010 é 0,730, ocupando a $1.021^{\text {a }}$ posição em relação aos 5.565 municípios do Brasil, e $23^{a}$ posição em relação aos outros 92 municípios do estado do Rio de Janeiro (ATLAS..., 2013a).

São José do Vale do Rio Preto possui área de $242,98 \mathrm{~km}^{2}$, população (Censo 2010) de 20.251 habitantes, densidade demográfica de $83,35 \mathrm{hab} / \mathrm{km}^{2}$ e IDHM 2010 de 0,660 . O município ocupa a $2.898^{a}$ posição, em 2010 , em relação aos 5.565 municípios do Brasil, e 81ª posição em relação aos 92 municípios fluminenses (ATLAS..., 2013b).

Sumidouro, município também situado na região serrana do Rio de Janeiro, possui área de $397,05 \mathrm{Km}^{2}$, população (censo 2010) de 14.900 habitantes, densidade demográfica de $37,58 \mathrm{hab} / \mathrm{km}^{2}$ e IDHM 2010 de 0,611, ocupando a $3.884^{a}$ posição dentre os municípios brasileiros e a $91^{\mathrm{a}}$ em relação aos 92 municípios fluminenses (ATLAS..., 2013c).

Os sujeitos participantes da pesquisa foram os 13 cirurgiōes-dentistas (CDs) que atuam nas unidades básicas de saúde da família desses municípios, distribuídos da seguinte forma: três CDs de Teresópolis; quatro CDs no município de São José do Vale do Rio Preto; e seis CDs no município de Sumidouro, de um total de 16 equipes cadastradas pelo Ministério da Saúde, segundo informações do CNES/DATASUS (2012). No momento da pesquisa, dois CDs do município de São José do Vale do Rio Preto haviam sido exonerados a pedido e um estava de licença médica, sendo excluídos da pesquisa.

Para preservar a identidade dos CDs, foram atribuídos códigos: CD1 a CD13. Para coleta dos dados, optou-se pela entrevista individual semiestruturada, 
com roteiro orientador. Após a transcrição, os dados foram analisados segundo a metodologia de Análise de Conteúdo (BARDIN, 2010) e a unidade de análise escolhida foi o tema, por ser considerada a mais útil unidade de análise (FRANCO, 2008).

O perfil dos CDs foi construído a partir dos dados de identificação contidos nos instrumentos da pesquisa. Os dados referentes ao perfil sociodemográfico foram distribuídos de acordo com as seguintes variáveis: idade, sexo, local de graduação e tempo de graduado. Já os dados referentes ao perfil da formação técnico-científica foram distribuídos de acordo como as variáveis "pós-graduação" e "área de especialização". Os dados relativos à organização do processo de trabalho dos cirurgiōes-dentistas no PSF foram analisados por agrupamento das categorias mais frequentes, de acordo com as falas. $\mathrm{O}$ agrupamento destas permtiu estabelecer as seguintes categorias: atividades clínicas, ações em instituições de convívio coletivo, visitas domiciliares e trabalho em equipe. As falas mais representativas foram escolhidas para serem discutidas.

A proposta de investigação foi submetida ao Comitê de Ética em Pesquisa da Fundação Oswaldo Cruz (Fiocruz) e aprovada sob o no 1102162.8.0000.5240. Seguindo recomendação da Resolução no 196/96 do Conselho Nacional de Saúde, todos os sujeitos convidados a participar do estudo foram esclarecidos sobre os objetivos da pesquisa e concordaram em participar assinando o Termo de Consentimento Livre e esclarecido.

A pesquisa é parte integrante da dissertação de mestrado intitulada Resíduos odontológicos em unidades de PSF: uma reflexão sobre o gerenciamento na atividade clinica e na assistência domiciliar, apresentada com vistas à obtenção do título de Mestre em Ciências na área de Saúde Pública, na Escola Nacional de Saúde Pública Sérgio Arouca - Fiocruz, em 2014.

\section{Resultados e discussão}

\section{Caracterização dos sujeitos da pesquisa Perfil sociodemográfico}

A odontologia caracterizou-se como uma profissão masculina até as últimas décadas, mas vem passando por um processo denominado, na literatura, como "feminilização", que se refere ao aumento da população feminina em profissōes historicamente exercidas por homens (COSTA et al., 2010). Há 40 anos, 90\% 
dos odontólogos brasileiros eram homens; atualmente, 56\% são mulheres (MORITA et al., 2010).

Os resultados, apresentados na tabela 1, mostram que 76,9\% dos cirurgióesdentistas participantes da pesquisa são do sexo feminino, o que sugere a feminilização da odontologia nas unidades de saúde estudadas, com um percentual acima da média nacional. No Brasil, 58\% dos cirurgióes-dentistas que atuam nas equipes de PSF são do sexo feminino (MORITA et al., 2010).

Tabela 1: Perfil dos entrevistados de acordo com a idade e sexo

\begin{tabular}{cc|c|c}
\hline \multicolumn{1}{c|}{ Características } & $\mathbf{n}^{\mathbf{0}}$ & $\%$ \\
\hline Idade (anos) & $31-40$ & 4 & 30,77 \\
\hline $41-50$ & 6 & 46,15 \\
\hline $51-60$ & 3 & 23,08 \\
\hline Sexo & Total & 13 & 100,00 \\
\hline & Masculino & 3 & 23,08 \\
\hline & Feminino & 10 & 76,92 \\
\hline
\end{tabular}

Fonte: Dados coletados pelos autores (2013).

Quanto à faixa etária (tabela 1), observa-se que há ligeira predominância da faixa etária de 41 a 50 anos, configurando profissionais com mais experiência. Difere do perfil nacional, no qual 68\% dos odontólogos que compóem as equipes de PSF têm menos de 40 anos, representando uma força de trabalho jovem (MORITA et al., 2010). Este resultado também difere daquele encontrado por Morita et al. (2010), onde o PSF representa a oportunidade de primeiro emprego.

E quanto ao local de formação, todos os entrevistados declararam ter se formado no Estado do Rio de Janeiro. Esse dado é confirmado no levantamento nacional, onde $86 \%$ dos odontólogos exercem sua profissão na mesma unidade federativa em que cursaram a graduação em odontologia (MORITA et al., 2010). Essa característica favorece o trabalho no PSF, visto que a atuação profissional na mesma unidade federativa em que cursou a graduação facilita a compreensão das características epidemiológicas da região. 


\section{Perfil da formação técnico-científica}

Quanto à época de formatura (tabela 2), seis odontólogos, representando 46,15\% do total, se formaram entre os anos 1980 e 1989; seis entre 1990 e 1999 e apenas um, representando $7,70 \%$, entre 2000 e 2009 .

Tabela 2: Perfil dos entrevistados de acordo com a época de formatura

\begin{tabular}{l|c|c}
\hline \multicolumn{1}{c|}{ Ano da formatura } & $\mathbf{n}^{\mathbf{0}}$ & $\%$ \\
\hline $1980-1989$ & 6 & 46,15 \\
\hline $1990-1999$ & 6 & 46,15 \\
\hline $2000-2009$ & 1 & 7,70 \\
\hline Total & 13 & $\mathbf{1 0 0 , 0 0}$ \\
\hline
\end{tabular}

Fonte: Dados coletados pelos autores (2013).

A maioria (92,3\%) apresenta mais de 14 anos de formados. Nessa época, os currículos universitários enfatizavam a fragmentação do tratamento odontológico e eram muito voltados para a especialização (VILLARINHO, 2007). Portanto, esses profissionais receberam uma formação voltada para as ações curativas e técnicas, com pouca ênfase nos fatores socioeconômicos e psicológicos do processo saúde-doença (ARAÚJO; DIMENSTEIN, 2006).

Esse problema ainda não foi superado. Apesar de as Diretrizes Curriculares Gerais da formação em saúde, aprovadas pelo Conselho Nacional de Educação, estabelecerem que os currículos devam dar ênfase a promoção da saúde, princípios e diretrizes do SUS, a educação superior em saúde no Brasil ainda segue um modelo de prática hospitalocêntrica, especializada e direcionada ao setor privado, não atendendo às necessidades sociais (ALMEIDA FILHO, 2013). Esse fato pode representar mais um desafio para o dentista do PSF, que necessita trabalhar integrado em uma equipe multidisciplinar. Aponta-se a necessidade de capacitação e educação permanente, de forma a suprir uma possível defasagem curricular.

Com relação à especialização, dez dentistas afirmaram ter pós-graduação, sendo que dois possuem duas pós-graduações. No entanto, apenas sete possuem cursos reconhecidos pelo Conselho Federal de Odontologia (CFO), e três são especialistas em Atenção Básica à Saúde da Família, curso não reconhecido pelo já citado órgão. O CFO apenas reconhece 19 especialidades odontológicas (MORITA et al., 2010). As especializaçōes citadas, reconhecidas, foram nas 
seguintes áreas: Odontopediatria, Saúde Coletiva, Endodontia, Saúde Pública, Ortodontia, Prótese dentária, Estomatologia e Odontologia do Trabalho.

É necessário esclarecer que, apesar de sete entrevistados possuírem cursos reconhecidos pelo CFO, apenas três efetuaram o respectivo registro desses cursos junto ao Conselho, representando $23 \%$ do total do estudo, e ficando muito próximo da média nacional, que segundo Morita et al. (2010) é de $25 \%$. O presente estudo confirma o que os autores apontaram: como o registro junto ao Conselho é uma prerrogativa do profissional, muitos não efetuam o registro da especialização. É necessário considerar que os números nacionais talvez não correspondam à realidade, e novos estudos se façam necessários (MORITA et al., 2010).

É fundamental apontar que, apesar de a especialização em Atenção Básica à Saúde da Família não ser reconhecida pelo CFO, esta especialidade contribui para a formação de profissionais engajados com a promoção da saúde e comprometidos com os objetivos do SUS. Desta forma, aponta-se a necessidade de revisão dos critérios de reconhecimento das especializações odontológicas.

\section{Organização do processo de trabalho da equipe de saúde bucal no PSF}

A partir daqui, inicia-se a análise da organização do processo de trabalho da equipe de saúde bucal. Os entrevistados abordaram temas como a composição da equipe e atividades desenvolvidas, a saber: atividades clínicas, açōes em creches e escolas, visitas domiciliares e reuniōes de equipe. Surgiram então as seguintes categorias: composição da equipe de saúde bucal, atividades clínicas, visita domiciliar, reunião de equipe, ações em instituições de convívio coletivo.

\section{Composição da equipe de saúde bucal}

As equipes de saúde bucal dos municípios estudados enquadram-se na modalidade I, que segundo a Portaria no 648 , de 28 de março de 2006, devem ser compostas por um cirurgião dentista e um auxiliar de consultório dentário - ACD (BRASIL, 2006). Porém alguns dentistas entrevistados declararam estar trabalhando sem auxiliar devido a problemas administrativos:

Estou sem auxiliar desde setembro do ano passado. Era contrato, terminou e o município não contratou outra. (CD-6).

Agora estou trabalhando com auxiliar, mas passei um ano sem. (CD 7)

Quem me ajuda é a auxiliar de serviços gerais. (CD 9) 
A Portaria no 648 estabelece atribuições específicas para o ACD, dentre elas proceder a desinfecção e esterilização do instrumental odontológico, realizar procedimentos educativos e preventivos como orientação quanto à técnica de escovação e higiene oral nos usuários antes do atendimento, e participar do desenvolvimento dos trabalhos da equipe de Saúde da Família no tocante à saúde bucal, dentre outras atribuições (BRASIL, 2006).

"As atividades educativas e preventivas, ao nível coletivo, devem ser executadas, preferencialmente pelo pessoal auxiliar. $O$ planejamento, supervisão e avaliação implicam participação e responsabilidade do CD” (BRASIL, 2004). Conclui-se que nessas unidades onde não há auxiliar de consultório dentário, o trabalho da equipe de saúde bucal fica prejudicado, podendo dificultar a reorganização da atenção básica.

\section{Atividade clínica}

A totalidade dos sujeitos deste estudo declarou exercer atividade clínica, dentro do consultório odontológico, durante a maior parte de sua carga horária de trabalho. Alguns afirmaram ainda, exercer exclusivamente esse tipo de atividade, caracterizando a adoção de um modelo assistencial tradicional. Apesar de o PSF preconizar ênfase nas atividades de prevenção e promoção da saúde, percebe-se que o modelo assistencial permanece vigente nesses municípios.

Apontam-se a grande demanda acumulada e a falta de planejamento como principais dificuldades para a incorporação de atividades extraclínicas no âmbito da saúde bucal nas unidades de Saúde da Família.

\section{Visita domiciliar}

Na Estratégia de Saúde da Família, a visita domiciliar é um procedimento rotineiro, preferencialmente realizado pelo agente comunitário de saúde (BRASIL, 2001b). Porém, quando realizada pela equipe de saúde bucal, caracteriza-se com um instrumento valioso para atingir os objetivos propostos pelo PSF, pois através da visita domiciliar, o profissional de saúde bucal se aproxima das famílias, reforçando o vínculo entre eles.

Segundo os relatos, esta é uma atividade pouco executada por esses profissionais: quatro odontólogos alegaram não fazer visitas domiciliares por falta de transporte e outros cinco declararam que esse procedimento não faz parte de sua rotina de trabalho. 
Então, visita domiciliar a gente fazia, mas tem mais ou menos um ano que a gente não faz porque está sem carro de visita e como é área rural é tudo muito longe. (CD 5).

Nós nos limitamos a ficar aqui mesmo. Aqui é muito raro fazer VD. (CD 8).

Dessa forma, a população com dificuldades de locomoção tem pouco ou nenhum acesso aos serviços de saúde bucal. Muñoz et al. (2012) afirmam que o mesmo ocorre no Chile, onde a atenção à saúde oferecida pelo Ministério da Saúde aos pacientes idosos e/ou acamados não inclui diagnóstico nem tratamento das patologias bucais, acarretando um estado de extrema deterioração da saúde bucal desse grupo. Espinoza et al. (2003), em estudo também realizado no Chile, encontraram algumas lesōes consideradas pré-cancerígenas em idosos assistidos pelo sistema de saúde público em Santiago. Os autores apontam a necessidade urgente da incorporação de exame da mucosa oral nas visitas domiciliares a acamados.

Dentre os profissionais que realizam a visita domiciliar com frequência, encontram-se relatos de visitas domiciliares realizadas com toda a equipe, e algumas realizadas apenas pelo odontólogo:

Eu costumo ir sozinha. Às vezes a auxiliar vai. Só às vezes. (CD 3).

As visitas domiciliares são realizadas junto com toda a equipe: médico, enfermeiro, técnico de enfermagem e agente comunitário. Às vezes junto com estudantes de medicina e enfermagem. (CD 1).

Com relação aos procedimentos realizados nessas visitas domiciliares, têm-se os seguintes relatos:

Eu faço alguns procedimentos. Pouca coisa. Só quando o paciente não pode mesmo vir aqui no consultório é que eu procuro fazer alguma coisa: uma extração que esteja muito fácil, uma raspagem... Remoção de sutura. Muitas vezes eu removo sutura também. O paciente às vezes extrai aqui comigo, e como ele é idoso, eu faço lá a remoção de sutura, para ele não ter que voltar. (CD 2).

Procedimentos educativos. Às vezes a colocação de um curativo, uma raspagem em pacientes que estão acamados. (CD 4).

Alguns procedimentos como escovação, orientação dos cuidadores extração, restauração temporária, exame bucal. (CD 1)

As visitas da equipe de saúde bucal às pessoas acamadas ou com dificuldades de locomoção, visando à identificação dos riscos e propiciando o acompanhamento e tratamento necessário, ampliam e qualificam as ações de saúde (BRASIL, 2001B). Além de possuir grande importância para o conhecimento da situação de 
saúde da família, a visita domiciliar proporciona o desenvolvimento de ações de

prevenção e promoção da saúde e possibilita a execução de alguns procedimentos, sobretudo para pessoas com dificuldade de locomoção (CALADO, 2002).

Sendo assim, aconselha-se a incorporação urgente da odontologia na assistência domiciliar a pessoas com dificuldades de locomoção, incluindo tratamentos restauradores básicos e reabilitação protética, de modo a melhorar a qualidade de vida desse grupo populacional.

\section{Trabalho em equipe}

Cada equipe de saúde da família deve funcionar como uma equipe de trabalho responsável pela saúde de $100 \%$ de sua população adscrita, deve conhecer a realidade da comunidade e identificar os determinantes de saúde da população e organizar as atividades segundo os riscos e vulnerabilidades individuais e coletivos. Para atingir esses objetivos, é necessário um trabalho em equipe (PARAGUAY, 2012).

As reuniōes de equipe são importantes dispositivos para criar uma interação entre os membros de uma equipe. A interação da equipe cria mecanismos de acolhimento e representa a melhor forma de integrar o paciente aos cuidados de um trabalho multidisciplinar (TEIXEIRA, 2006). Para o cirurgião-dentista inserido no PSF, essas reuniōes criam a possibilidade de facilitar o trabalho em equipe, pois para ele o trabalho em equipe, além de introduzir o "novo", afronta valores, lugares e poderes consolidados pelas práticas dos modelos anteriores, tornando-se um desafio para ele (VILLARINHO et al., 2010).

Além disso, o Ministério da Saúde estipulou como função da equipe de saúde bucal a interação com profissionais de outras áreas, com o objetivo de ampliar o conhecimento, permitindo a abordagem do indivíduo como um todo, considerando o contexto socioeconômico ecultural no qual ele está inserido (BRASIL, 2004).

Esse objetivo aparece bem contemplado nos relatos abaixo:

O dentista participa das reuniões de equipe. Geralmente de $15 \mathrm{em} 15$ dias. A gente fala sobre as áreas, sobre os problemas da comunidade, as agentes de saúde trazem os problemas para a gente. Questões burocráticas também são discutidas. Agora a gente está querendo fazer um planejamento para realizar uma capacitação, onde em cada reunião um tema será abordado, até para dar uma capacitação para as ACS, pois o curso introdutório delas foi muito fraco. (CD 4).

Nessas reuniōes são programadas as ações e visitas domiciliares: discutem-se alguns casos clínicos e problemas da equipe. (CD 1) 
Apesar da importância da reunião de equipe, este estudo encontrou algumas equipes de saúde bucal que não participam dessas reuniões, como relatado abaixo:

Quase nunca ocorre reunião de equipe aqui. E quando ocorre, o dentista não participa. (CD 12).

Não há reunião de equipe nessa unidade. (CD 3).

Em alguns casos, quando a reunião ocorre, tem função apenas administrativa, como se verifica no relato abaixo sobre o tema da reunião:

É mais mesmo o andamento do trabalho. Pois aqui na unidade a gente não tem telefone, não tem internet, então depende muito do trabalho do agente comunitário de saúde para poder marcar e remarcar pacientes, levar papel de referência e contra referência. (CD 5).

Nesses relatos, percebe-se que não ocorre troca de saberes entre os profissionais dessas equipes. Em alguns casos, a equipe de saúde bucal não se sente parte da equipe multiprofissional da unidade de saúde onde atua.

\section{Ações em instituições de convívio coletivo}

A maioria dos entrevistados declarou fazer alguma atividade em instituições de convívio coletivo como creches, escolas e asilos. As principais atividades citadas foram; palestras, atividades de educação em saúde, escovação supervisionada, aplicação tópica de flúor, exame bucal com finalidade de estimar as necessidades e separar os grupos de riscos.

Alguns declararam não realizar essas ações por falta de transporte:

Não estamos indo às escolas, pois estamos sem carro, e como aqui é zona rural, é tudo muito longe.(CD 6).

A equipe deve conhecer a realidade da comunidade onde atua e as características da população adstrita (faixa etária da população, condições socioeconômicas e doenças prevalentes, entre outras) para depois poder planejar as ações de saúde. Nos relatos abaixo, percebe-se que, apesar da importância que o território exerce nas atividades de uma equipe de PSF, alguns profissionais ainda têm dificuldade de reconhecer sua área de abrangência.

Tem uma escola aqui próximo. Só que a enfermeira falou que tem outra escola que pertence a nossa área. A gente fica meio perdido com relação a área de abrangência. A enfermeira falou isso, só que no mapa não aparece essa escola. (CD 2).

Não sei quantas escolas são. Não conheço bem a área. (CD 9) 
Percebe-se, por meio desses relatos, que não ocorre troca de saberes entre os profissionais dessas equipes. E mais uma vez, há casos em que a equipe de saúde bucal não se sente parte da equipe multiprofissional da unidade de saúde.

\section{Considerações finais}

A inserção da equipe de saúde bucal no Programa Saúde da Família representou um grande avanço na atenção básica, pois ampliou o acesso da população à assistência odontológica, priorizando ações de prevenção e promoção da saúde bucal. Porém, a realidade observada em alguns municípios da região serrana do Rio de Janeiro aponta que a filosofia do PSF foi parcialmente seguida, pois o CD ainda encontra dificuldades para conhecer e atuar na realidade epidemiológica da população adstrita.

Apesar de o perfil do CD encontrado nesses municípios revelar potencialidades para a transformação das práticas em saúde bucal, é necessário estimular o trabalho do $\mathrm{CD}$ em equipes multiprofissionais e melhorar as condições de trabalho desses profissionais, oferecendo meio de transporte, de forma a facilitar o acesso às famílias e o conhecimento do território. Só assim será possível conhecer as necessidades epidemiológicas e sanitárias das comunidades.

Este estudo não teve o objetivo de esgotar o tema, e sim estimular novas pesquisas na área. Devido à importância de se conhecer o perfil dos profissionais de saúde para a elaboração de políticas públicas e a escassez dessas informaçôes, espera-se que os resultados aqui apresentados contribuam para o planejamento e implementação de políticas de formação e melhor inserção do odontólogo nas equipes de Saúde da Família. ${ }^{1}$

\section{Referências}

ALMEIDA FILHO, N.M. Contextos, impasses e desafios na formação de trabalhadores em Saúde Coletiva no Brasil. Cien Saúde Colet, Rio de Janeiro, v. 18, n. 6, p. 1677-1682, 2013. ARAÚJO, Y.P.; DIMENSTEIN, M. Estrutura e organização do trabalho do cirurgiãodentista no PSF de municípios do Rio Grande do Norte. Cienc. Saúde Colet, Rio de Janeiro, v. 11, v. 1, p. 219-227, 2006.

ATLAS DO DESENVOLVIMENTO HUMANO NO BRASIL. São José do Vale do Rio Preto. Rio de Janeiro, 2013(b). Disponível em: http://www.atlasbrasil.org.br/2013/perfil/ sao-jose-do-vale-do-rio-pretorj. Acesso em: 31 jul. 2013. 
. Sumidouro. Rio de Janeiro, 2013(c). Disponível em: http://www.atlasbrasil.org. br/2013/perfil/sumidourorj. Acesso em: 31 jul. 2013.

. Teresópolis. Rio de Janeiro, 2013(a). Disponível em: http://www.atlasbrasil.org. br/2013/perfil/teresopolisrj. Acesso em: 31 jul. 2013.

BARDIN, L. Análise de conteúdo. Lisboa. Ediçōes 70, 2010.

BRASIL. Lei no 8.080, de 19 de setembro de 1990. Dispõe sobre as condições para a promoção e recuperação da saúde, a organização e o funcionamento dos serviços correspondentes e dá outras providências. Diário Oficial [da] República Federativa do Brasil, Brasília, 19 set. 1990. BRASIL. Ministério da Saúde. Diretrizes da Política Nacional de Saúde Bucal. Brasília: Ministério da Saúde, 2004.

- Guia Prático do Programa Saúde da Família. Brasília: Ministério da Saúde, 2001(a). Portaria no 1.444 , de 28 de dezembro de 2000. Estabelece incentivo financeiro para a reorganização da atenção à saúde bucal prestada nos municípios por meio do Programa de Saúde da Família. Diário Oficial [da] República Federativa do Brasil, Brasília, dez. 2000. Portaria no 267, de 06 de março de 2001. Portaria de normas e diretrizes da Saúde Bucal. Diário Oficial [da] República Federativa do Brasil, Brasília, seção 1, p. 67, seção 1, mar. 2001(b).

. Portaria no 648, de 28 de março de 2006. Aprova a Política Nacional de Atenção Básica, estabelecendo a revisão de diretrizes e normas para a organização da Atenção Básica para o Programa Saúde da Família (PSF) e o Programa Agentes Comunitários de Saúde (PACS). Diário Oficial [da] República Federativa do Brasil, Brasília, 2006.

CALADO, G.S. A inserção da equipe de saúde bucal no programa de saúde da família. 137p. Dissertação (Mestrado em Saúde Pública) - Escola Nacional de Saúde Pública, Fiocruz. Rio de Janeiro, 2002.

CADASTRO NACIONAL DOS ESTABELECIMENTOS DE SAÚDE DO BRASIL. Equipes de Saúde, Rio de Janeiro. Ministério da Saúde. Disponível em: http://www.tabnet. datasus.gov.br/cgi/deftohtm.exe?cnes/cnv/equiperj.def. Acesso em: 10 out. 2012.

COSTA, S.M.; DURÃES, S.J.A.; ABREU, M.H.N.G. Feminilização do curso de odontologia da Universidade Estadual de Montes Claros. Cien Saude Colet. Rio de Janeiro, v. 15, supl. 1, p. 1865-1873, 2010.

ESPINOZA, I. et al. Prevalence of oral mucosa lesions in elderly people in Santiago, Chile. J.Oral Pathol. Med., v. 32, n. 10, p. 571-575, 2003.

FRANCO, M.L.P.L. Análise de conteúdo. 3 ed. Brasília: Liber Livro, 2008.

MORITA, M.C.; HADDAD, A.E.; ARAÚJO, M.E. Perfil atual e tendências do cirurgiãodentista brasileiro. Maringá: Dental Press, 2010. 
MUÑOZ, A.D. et al. Salud bucodental de postrados severos. Int. J. Odontostomat, v. 6, n.

2, p. 181-187, 2012.

OLIVEIRA J.L.C.; SALIBA, N.A. Atenção Odontológica no Programa de Saúde da Família de Campos dos Goytacazes. Cienc Saude Colet. Rio de Janeiro, v. 10, p. 297-302, 2005.

PARAGUAY. Ministério de Salud Pública y Bienestar Social. Guía de organización del trabajo en equipo. Série atención integral a la família y comunidade para los Equipos de Salud de la Família. Assunción: Ministério de Salud Pública y Bienestar Social, 2012.

PINTO, V.G. Saúde Bucal Coletiva. São Paulo: Santos, 2000.

RODRIGUES, A.A.; BONFIM L.S. Saúde Bucal em um Programa da Saúde da Família em município do semiárido baiano (Feira de Santana): organização e micropolítica. Rev. APS, Juiz de Fora, v. 13, n. 1, p. 96-108, 2010.

RONCALLI, A.G.A Organização da demanda em serviços públicos de saúde bucal. Universidade, equidade e integralidade em saúde bucal coletiva. Tese (Doutorado em Odontologia) - Universidade Estadual Paulista Júlio de Mesquita Filho, Faculdade de odontologia, Araçatuba-SP: 2000. 238p.

TEIXEIRA, M.C.B. A dimensão cuidadora do trabalho de equipe em saúde e sua contribuição para a odontologia. Cien. Saúde Colet. Rio de Janeiro, v. 11, n. 1, p. 45-51, 2006.

VILLARINHO, S.M.; MENDES, R.F.; PRADO JÚNIOR, R.R. Perfil dos cirurgiōesdentistas integrantes do Programa Saúde da Família em Teresina-PI. Rev.Odonto.Cien, v. 22, n. 55, p. 48-54, 2007.

WALTER, L.R.F.; FERELLE, A.; ISSAO, M. Introdução. In: . Odontologia para o bebê. Londrina: Artes Médicas, 1996. p. 3-5.

\section{Nota}

${ }^{1}$ L.B. de Moraes participou da concepção, desenho, análise e interpretação dos dados e redação do artigo. D.C. Kligerman realizou a revisão crítica do conteúdo intelectual do artigo. S.C. Cohen aprovou a versão final do artigo a ser publicada. 


\section{Abstract}

Analysis on the socio-demographic profile and dental surgeon's work process in the Family Health Program, in three cities of the mountain region of the state of Rio de Janeiro The inclusion of dentistry in the Family Health Program aimed to reorganize the care model, expanding the population's access to oral health services, ensuring comprehensive care through the establishment of territorial bond. In this context, the study aimed to evaluate the profile of dental surgeons inserted into the program and analyze the working process of the dental team in three municipalities in the mountain region of the State of Rio de Janeiro, investigating whether it replaced the traditional model of service, by that focused on the SUS principles. This is an exploratory study based on interviews. The profile of the dental surgeon found in these municipalities showed potential for the transformation of practices in oral health, but the analysis of the labor process identified little involvement of these professionals with the community life conditions and difficulty to work in multidisciplinary teams. It pointed out the need for public policies that incorporate training programs for the dental surgeon to act in line with the guidelines of the Family Health Program. 